\title{
PERCEPÇÕES SOBRE O APLICATIVO FOQ1 QUÍMICA POR ESTUDANTES DE UMA ESCOLA PÚBLICA
}

\author{
PERCEPTIONS ABOUT THE FOQ1 CHEMICAL APPLICATION BY STUDENTS \\ OF A PUBLIC SCHOOL
}

\section{PERCEPCIONES SOBRE LA APLICACIÓN QUÍMICA FOQ1 POR PARTE DE ESTUDIANTES DE UNA ESCUELA PÚBLICA}

\author{
Jocimario Alves Pereira ${ }^{1}$ (D) 9 \\ Bruno Silva Leite ${ }^{2}$ (D) 9
}

\begin{abstract}
RESUMO
A utilização das Tecnologias Digitais de Informação e Comunicação (TDIC), em especial dos Recursos Didáticos Digitais (RDD), tem transformado muitas práticas docentes contribuindo para a construção do conhecimento dos seus estudantes. Neste sentido, essa pesquisa tem por objetivo investigar a percepção dos estudantes de uma escola pública na utilização do aplicativo para dispositivo móvel denominado FoQ1 Química nos estudos da Química. Para isso, a pesquisa apresenta um estudo de caso realizado com 75 estudantes de quatro turmas do ensino médio (duas turmas do primeiro ano e duas turmas do segundo ano). A pesquisa foi realizada em quatro (4) etapas: (1) apresentação do app FoQ1 Química; (2) aplicação de um questionário avaliativo; (3) realização de uma entrevista não-diretiva; (4) análise das respostas do questionário avaliativo e da entrevista não-diretiva. Os resultados mostram que o aplicativo FoQ1 Química pode ser um RDD auxiliar no processo de ensino e aprendizagem da Química, proporcionando aos estudantes possibilidades de construírem seu conhecimento de forma simples e objetiva. Embora alguns estudantes tenham apresentado dificuldades nos conteúdos da Química, o uso do aplicativo FoQ1 Química pode contribuir para a compreensão destes conteúdos. O desenvolvimento de aplicativos com o intuito de ajudar no ensino de Química se mostra como uma alternativa proeminente, tendo o professor como seu principal desenvolvedor e os estudantes como os principais usuários.
\end{abstract}

Palavras-chave: TDIC; Aplicativo móvel; Ensino de Química; Fórmulas e Equações Químicas.

\begin{abstract}
The use of Digital Information and Communication Technologies (DICT), especially of Digital Didactics Resources (DDR), has transformed many teaching practices, contributing to the construction of the knowledge of its students. In this sense, this research aims to investigate the perception of students of a public school in the use of the application for mobile device called FoQ1 Química in the studies of Chemistry. For this, the research presents a case study carried out with 75 students from four high school classes (two classes from the first year and two classes from the second year). The research was carried out in four (4) stages: (1) presentation of the FoQ1 Química app; (2) application of an evaluative

\footnotetext{
${ }^{1}$ Mestre em Química pela Universidade Federal Rural de Pernambuco (UFRPE). Professor de Ciências da Escola Municipal de Ensino Fundamental Raimunda Leite Sobrinha (EMEFRLS), Conceição, Paraíba, Brasil. Endereço para correspondência: Rua Paulino dos Santos Coelho, 421 - Ap. 302 - Jardim Cidade Universitária, João Pessoa, Paraíba, Brasil. E-mail: mario.alves@hotmail.com.

${ }^{2}$ Doutor em Química pela Universidade Federal de Pernambuco (UFPE). Professor de Química e de Tecnologias no Ensino de Química da Universidade Federal Rural de Pernambuco (UFRPE), Recife, Pernambuco, Brasil. Endereço para correspondência: Universidade Federal Rural de Pernambuco, Departamento de Educação, Dois Irmãos, Recife, Pernambuco, Brasil. E-mail: brunoleite@ufrpe.br
} 
questionnaire; (3) conducting a non-directive interview; (4) analysis of the responses to the evaluation questionnaire and the non-directive interview. The results show that the FoQ1 Química app can be an auxiliary DDR in the teaching and learning process of Chemistry, providing students with possibilities to build their knowledge in a simple and objective way. Although some students presented difficulties in the contents of Chemistry, the use of the FoQ1 Química app can contribute to the understanding of these contents. The development of applications in order to help in the teaching of Chemistry is shown as a prominent alternative, with the teacher as its main developer and students as the main users.

Keywords: DICT; Mobile application; Chemistry teaching; Chemical Formulas and Equations.

\section{RESUMEN}

El uso de las Tecnologías Digitales de la Información y la Comunicación (TDIC), especialmente de los Recursos Digitales Docentes (RDD), ha transformado muchas prácticas docentes, contribuyendo a la construcción del conocimiento de sus estudiantes. En este sentido, esta investigación tiene como objetivo investigar la percepción de los estudiantes de una escuela pública en el uso de la aplicación para dispositivos móviles denominada FoQ1 Química en los estudios de Química. Para ello, la investigación presenta un caso de estudio realizado con 75 alumnos de cuatro cursos de bachillerato (dos cursos del primer año y dos cursos del segundo año). La investigación se realizó en cuatro (4) etapas: (1) presentación de la aplicación FoQ1 Química; (2) aplicación de un cuestionario evaluativo; (3) realizar una entrevista no directiva; (4) análisis de las respuestas al cuestionario de evaluación y la entrevista no directiva. Los resultados muestran que la aplicación FoQ1 Química puede ser un RDD auxiliar en el proceso de enseñanza y aprendizaje de la Química, brindando a los estudiantes posibilidades para construir sus conocimientos de una manera sencilla y objetiva. Aunque algunos estudiantes han experimentado dificultades en los contenidos de Química, el uso de la aplicación FoQ1 Química puede contribuir a la comprensión de estos contenidos. El desarrollo de aplicaciones con el fin de ayudar en la enseñanza de la Química se muestra como una alternativa destacada, con el profesor como principal desarrollador y los estudiantes como principales usuarios.

Palabras clave: TDIC; Aplicación móvil; Enseñanza de Química; Fórmulas químicas y ecuaciones.

\section{INTRODUÇÃO}

A educação é um processo proativo e coeso, fundamentado pelas relações socioculturais, políticas e econômicas, que evolui e se modifica com o passar dos tempos, de acordo com as necessidades do tempo, espaço e objetivos dos sujeitos. Em vista disso, há uma necessidade de pesquisa, análise e debate, dentro de um circuito contínuo que promova a construção do conhecimento de forma democrática e plural. Para que esta ação ocorra de maneira equilibrada, diversas variáveis são colocadas a ponto, como os recursos, ferramentas, metodologias, e que devem estar sempre sobre avaliação para que haja um entendimento sobre os caminhos mais efetivos na construção do conhecimento.

Dentro desta perspectiva, encontra-se uma observação sobre as Tecnologias Digitais de Informação e Comunicação (TDIC), assim como Recursos Didáticos Digitas (RDD) e Aplicativos (apps), de "como" e o "quanto" eles podem contribuir no processo de ensino e aprendizagem, reforçando a engrenagem das atividades educacionais. A literatura tem apontado 
resultados positivos em relação ao uso de TDIC, RDD e apps, nos processos educacionais, com boa aceitabilidade dos estudantes na utilização destes recursos, promoção de democratização das informações e autonomia dos sujeitos. Todavia, é importante salientar que nem tudo que é tecnológico e novo, é intrinsicamente favorável ao processo de ensino e aprendizagem (LEITE, 2018; SILVA et al., 2018).

Neste sentido essa pesquisa, que é parte de uma dissertação de mestrado que buscou responder o questionamento de como um Recurso Didático Digital (RDD), como um app, pode auxiliar no processo de ensino e aprendizagem de Química? Teve como objetivo investigar a percepção dos estudantes de uma escola pública sobre a utilização do aplicativo FoQ1 Química, em estudos na disciplina de Química. Desse modo, essa é uma maneira de compreender o potencial do app como um RDD, pelo prisma dos principais interessados que são os estudantes, o que dá condições de assimilar ideias que podem orientar melhorias do FoQ1 Química, como também apontar possibilidades para o desenvolvimento de outros RDD. Essa análise sobre o FoQ1 Química é elementar, pois o app é um recurso que trata de Fórmulas Equações e Modelos Matemáticos Aplicados na Química (FEMAQ), tema muito explorado nas avaliações institucionais, mas que é pouco discutido em pesquisas científicas e também pouco explorado nos apps (TORI, 2016; CARVALHAES, 2016).

\section{REFERENCIAL TEÓRICO}

A utilização dos RDD no ensino de Química apresenta inúmeras possibilidades, construções e reconstruções de metodologias com uso desses recursos (LOCATELLI; ZOCH; TRENTIN, 2015; TORI, 2017). Essa perspectiva parte da possibilidade de que esses recursos permitem maior autonomia para o aprendizado e fortalecem a construção do saber possibilitando maior interdisciplinaridade, contextualização e interações socioculturais, como destacam Locatelli, Zoch e Trentin (2015).

Contudo, os processos educacionais no Brasil ainda são distintos, pois há diversas realidades sociais, culturais e ideológicas. Precisam-se de grandes investimentos, pesquisas e formações para que, assim, atinja todos os estudantes (SILVA; CARVALHO, 2017). Para a efetividade do uso das TDIC no ensino, há necessidade de qualificação e formação contínua dos professores, para que o uso delas tenha objetivo específico e a aplicação seja horizontal. Sousa Neto e Mendes (2017) defendem 


\begin{abstract}
a ideia de que a fluência digital promove a segurança e confiança profissional do professor, conduzindo-o aos usos pedagógicos das TDIC na escola. Todavia, essa fluência precisa ser construída a partir da sua tomada de consciência, construída coletivamente, para se apropriar das TDIC como instrumentos culturais de aprendizagens e depois ensinar com o uso delas, assumindo assim uma postura ativa em relação à sua formação. Para isso, é fundamental que o professor reconheça os conhecimentos técnicos/tecnológicos, adquiridos na formação inicial ou continuada, de forma autônoma ou coletiva, entre os seus saberes pedagógicos necessários à docência e os relacione aos saberes do conteúdo disciplinar (p. 520).
\end{abstract}

Mesmo com a evolução das metodologias de ensino, o professor continua sendo peça rimordial para o ensino. Nesse enquadramento, ele é o responsável por diagnosticar e promover mudanças no sistema educacional. Contudo, é notório apontar que, mesmo o professor tendo este papel crucial, os estudantes devem ser sempre levados em consideração e colocados no centro dos objetivos da aprendizagem (LEITE, 2018), o que notadamente evidencia a necessidade de maior sensibildiade dos professores e do sistema de ensino às carências e anseios dos estudantes.

Todavia, as TDIC podem dar um suporte pujante aos estudantes, pois permitem a construção do saber em tempo e espaço distintos a cada sujeito, promovendo processos ímpares. (MORAN, 2014). Ziede et al. (2016) corroboram com Moran (2014), acrescentando que as TDIC são mais do que recursos auxiliares, elas apresentam condições para construção isomérica do ensino, dando liberdade e democratização à informação e construção do conhecimento, isto é, não são apenas um recurso para o ensino, mas os novos alicerces para processo de ensino e aprendizagem.

O reconhecimento da relevância das TDIC na educação tem sido observado nas pesquisas, porém práticas com seu uso ainda se aparentam de maneira isolada. Além disto, outro fator corrobora para dificultar o uso das TDIC em sala de aula: as condições socioeconômicas. Todavia, uma possibilidade de superar essas dificuldades pode ocorrer através dos dispositivos móveis, em especial,os smartphones, pois são dispositivos que são populares em diversas partes da sociedade (não em todas), possibilitando a utilização de aplicativos que podem diminuir as barreiras sociais (POSSA et al., 2015; SANTOS; ROCHA; LINCK, 2018). Reinaldo et al. (2016) falam que

Smartphones assumem o papel de agentes transformadores e revolucionários dessa sociedade contemporânea. Também oferecem a singularidade ao seu utilizador, proporcionam acesso à informação de maneira facilitada e gratuita, portabilidade e outros (p. 771). 
Os smartphones são considerados como recursos proeminentes no processo de ensino e aprendizagem da Química (LEITE, 2015), que vem contribuindo para (re)construção de ações apropriadas para a construção do conhecimento.

As TDIC no ensino de Química se tornam sólidas e imperativas, uma vez que a Química, considerada uma disciplina abstrata, faz uso de muitos símbolos para sua compreensão, carecendo de recursos que permitam sua representação. De acordo com Machado (2016), a expressão concedida pelos recursos tecnológicos ao ensino de Química dá uma sustentação sobre a percepção do conhecimento e aproxima todos os níveis de representatividade (macroscópico, submicroscópico e simbólico). Contudo, um fator que deve ser considerado, além da representatividade, é a comunicação que ocorre por meio da disponibilidade da informação entre redes sociais e banco de dados através de sites e aplicativos (PEREIRA; SILVA JÚNIOR; SILVA, 2019). Hoje se tem o "mundo na palma da mão" com a conectividade proposta pela internet e pelos celulares, o que dá autonomia e protagonismo aos educandos (LEITE, 2014). Reforçando essa filosofia, encontra-se o discurso de Neves e Melo (2014):

\footnotetext{
Dentre as principais potencialidades oferecidas pelos dispositivos móveis para o ensino e aprendizagem destacam-se a ampliação e a facilidade do acesso aos materiais didáticos, à possibilidade de criação de comunidades para uma aprendizagem ativa, interativa e colaborativa e o intercâmbio multicultural proporcionado a partir da interconexão entre diferentes pessoas e culturas (p. 3).
}

Desta maneira, a melhoria dos recursos visuais, mecanismos de exploração ou representações didáticas, permitem melhores expressões, comunicações e maior atenção aos processos de ensino e aprendizagem. Destaca-se que os recursos digitais proporcionam desenvolvimento educacional não apenas na escola, mas também fora dela, o que torna o ensino democrático e amplo. Outro fato que instiga é que as tecnologias fazem parte do dia a dia da sociedade, e como tal deveria fazer parte do processo de ensino e aprendizagem como fonte de contextualização (SILVA; SILVA; SILVA, 2015).

No conceito de Costa, Duqueviz e Pedroza (2015), as tecnologias no ensino são instrumentos auxiliares que não substituem o professor, mas propiciam descentralização do ensino. Na Química, há adaptações dos mecanismos tecnológicos, como há recursos direcionados ao processo de ensino, conduzindo aos mais diversos temas (PEREIRA, 2014), e diante das necessidades sociais, os aplicativos desenvolvidos para o ensino de Química agem como "laboratórios", pois permitem realizar atividades apropriadas às realidades das quais os educandos fazem parte (SILVA et al., 2018). Isso também influi na formação dos professores, 
pois devem acompanhá-los. Por exemplo, o professor de Química tem uma grande responsabilidade por agregar todas as interfaces da disciplina, propondo interdisciplinaridade, contextualização e domínio das ferramentas digitais (KLEIN; SANTOS; SOUZA, 2018).

Nesse contexto, o ensino se torna mais significativo e instigante, o que leva a sempre estar desenvolvendo e analisando esses tipos de recursos e metodologias, provocando uma reflexão e consequente aperfeiçoamento da educação e da sociedade (SILVA et al., 2018).

Segundo Araújo (2016), o uso de celular nas aulas de Química viabiliza uma melhor interação, como também motiva os estudantes, visto ser um dispositivo que os estudantes têm certo domínio. Os celulares têm grandes potencialidades no processo de ensino e aprendizagem, pois possuem funções diversas, e os aplicativos que podem ser instalados dão essas condições para as inúmeras possibilidades. De acordo com Nichele e Schlemmer (2014), os aplicativos para celulares e tablets possuem amplas características que os incrementam: como os valores financeiros dos aplicativos, em que sua maioria é baixado de graça; são de fácil instalação; e podem ser baixados em pouco tempo. Essas ferramentas possuem uma interface agradável, criativa e dinâmica que entusiasma seu uso para os mais variados fins, inclusive no processo de ensino e aprendizagem. Assim, Gouveia e Pereira (2015) reforçam

[...] acreditamos que a utilização adequada do celular na sala de aula, desperta uma expectativa diferente, por se tratar de uma questão que até o momento causa polêmica. A visão que a maioria tem em relação a esse uso, precisa ser analisada por todos, não só os professores, mas também por parte dos governos, para que estes possam criar Políticas Públicas direcionadas a mais investimentos na inclusão digital através do celular também (p. 45).

É notável que quando os aplicativos são indicados, demonstrados ou apresentados em estudos ou pesquisas, são bem aceitos pelos professores e estudantes, o que corrobora com o discurso de Gouveia e Pereira (2015). Ainda, de acordo com Vieira et al. (2019), o uso de aplicativos no processo de ensino e aprendizagem faz parte do processo de evolução educacional, ocorrido devido às mudanças sociais, culturais, econômicas e tecnológicas, ou seja, transitoriamente o uso de aplicativos no ensino e aprendizagem passará de exceção para ser uma regra.

O uso de aplicativos para o ensino de Química é muito dinâmico, pois muitos são jogos, redes sociais, quiz, além de ter dispositivos direcionado aos estudos, como ebooks, manuais, simuladores, dentre outros. Isso eleva o ensino de Química a um patamar diversificado, indo além do quadro e pincel, livros e laboratórios, chegando a mecanismos populares que estão nas mãos dos estudantes em todos os momentos, o que facilita as estratégias dos professores, ou 
seja, faz com que se desenvolva significados no ensino (SILVA et al., 2018; VIEIRA et al., 2019).

\section{METODOLOGIA}

Com o intuito de investigar a percepção dos estudantes de uma escola pública da Paraíba sobre a utilização do aplicativo FoQ1 Química, esta pesquisa se configura como um estudo de caso que, que de acordo André (2019) pode ser uma ação executada sobre parcelas educacionais, permitindo análises sobre aspectos variados nas suas práticas típicas e instintivas.

O aplicativo foi elaborado para auxiliar nos estudos da Química, permitindo acesso a materiais de estudo, além de redirecionamento para download dos materiais em formato de documento portátil (Portable Document Format - PDF), possibilitando a impressão destes e dando maior comodidade aos usuários.

As ações desta pesquisa foram realizadas com 75 estudantes de quatro turmas do ensino médio, sendo duas turmas do primeiro ano (50 estudantes) e duas turmas do segundo ano (25 estudantes), os quais tiveram autorização prévia de seus responsáveis através do Termo de Consentimento Livre e Esclarecido (TCLE), conforme as normas e diretrizes das pesquisas científicas que envolvem seres humanos (BRASIL, 2019). O trabalho foi dividido em quatro (4) etapas descritas a seguir.

A primeira etapa foi a apresentação do app FoQ1 Química para os estudantes. Inicialmente o app foi apresentado ao professor da disciplina de Química da escola, através de uma reunião on-line via Google Meet ${ }^{3}$, depois o professor de Química da instituição apresentou aos estudantes por meio de aulas virtuais ${ }^{4}$ com o Google Sala de Aula, no qual foi indicado para que os estudantes realizassem o download do FoQ1 Química.

Na segunda etapa, realizou-se a aplicação de um questionário avaliativo (Quadro 1) de cunho quanti-qualitativo, que permitiu relacionar dados estatísticos e justificá-los em aspectos argumentativos, aprofundando as compreensões individuais para construção do entendimento

\footnotetext{
${ }^{3}$ Recurso de comunicação por vídeo desenvolvido pelo Google, possibilita a participação de até 250 pessoas ao mesmo tempo, permite gravações e não há limites de tempo para seu uso (GONÇALVES, 2020).

${ }^{4}$ As aulas virtuais ocorreram em consequência da pandemia do SARS-Cov-2, o qual provocou o cancelamento das aulas presenciais via decretos, normativos e ofícios da Secretária Estadual de Saúde da Paraíba (SES-PB), Secretária Estadual de Educação Ciências e Tecnologia da Paraíba (SEECT-PB) e Secretária Estadual de Administração da Paraíba (SEA-PB), embasado na orientação da Organização Mundial de Saúde (OMS) e do Ministério da Saúde (MS), (BEZERRA et al, 2020; PARAÍBA, 2020a; PARAÍBA, 2020b).
} 
coletivo das perspectivas do estudantes sobre o FoQ1 Química (PASCHOARELLI; MEDOLA;

BONFIM, 2015; MOREIRA; DIEB, 2018).

1 - Você está participando de alguma atividade de ensino e aprendizado à distância:

Sim ( ) Não ( )

(se a resposta for NÃO pular para questão 4 se a resposta for SIM responder a próxima pergunta)

2- Com o início das atividades remotas, qual plataforma digital você está utilizando para acompanhar as aulas?

(Pode marca mais de uma alternativa se for o caso)

Google Sala de Aula ( ) Zoom ( ) Google Meet ( ) Moodle ( ) WhatsApp ( ) Outras. Quais?

3 - Classifique os itens de acordo com o questionamento abaixo:

\begin{tabular}{|l|l|l|l|l|l|}
\hline $\begin{array}{l}\text { Como você avalia esse } \\
\text { mecanismo de ensino diante da }\end{array}$ & Muito Ruim & Ruim & Regular & Bom & Muito Bom \\
atual situação de isolamento & & & & \\
social & & & & \\
\hline $\begin{array}{l}\text { O uso dessas plataformas é } \\
\text { fáceis e consigo aprender com } \\
\text { elas. }\end{array}$ & & & & \\
\hline
\end{tabular}

4 - Você baixou o aplicativo FoQ1 Química:

Sim ( ) Não ( )

(se a resposta for SIM pular para questão 7 se a resposta for NÃO responder a próxima pergunta)

5 - Você teve acesso ao material do FoQ1 Química por outros meios?

Sim ( ) Não ( )

(se a resposta for SIM pular para questão 8 se a resposta for NÃO responder a próxima pergunta)

6 - Por favor, explique o motivo pelo qual não baixou o aplicativo FoQ1?

7 - Você utiliza outros aplicativos para estudos?

8 - Quais aplicativos usa para estudos?

9 - Classifique os itens de acordo com o questionamento abaixo:

\begin{tabular}{|l|l|l|l|l|l|}
\hline $\begin{array}{l}\text { Como você avalia o uso de } \\
\text { aplicativos para estudar. }\end{array}$ & Muito Ruim & Ruim & Regular & Bom & Muito Bom \\
\hline $\begin{array}{l}\text { O uso dessas plataformas é } \\
\text { fáceis e consigo aprender com } \\
\text { elas. }\end{array}$ & & & & & \\
\hline
\end{tabular}

10 - Você conhece algum aplicativo com a mesma temática do FoQ1?

Sim ( ) Não ( )

(se a resposta for NÃO pular para questão 12 se a resposta for SIM responder a próxima pergunta)

11 - Quais outros aplicativos da temática do FoQ1 Química você conhece?

12 - Você utilizou o aplicativo FoQ1 Química nos seus estudos?

13 - Por que você não usou o FoQ1 Química no seus estudos?

14 - Classifique os itens de acordo com o questionamento abaixo:

Como você avalia a utilidade do aplicativo FoQ1 Química nos estudos de Química.

Como você avalia a utilidade do aplicativo FoQ1 Química nos estudos de fórmulas, equações e modelos matemáticos aplicados na Química.

Como você avalia o conteúdo do FoQ1 Química.

Como você classifica sua perícia para compreensão dos fenômenos químicos após uso do FoQ1 Química. 
Como você classifica sua perícia para compreensão dos conceitos químicos após uso do FoQ1 Química.

Como você classifica sua perícia para realização de cálculos na Química após uso do FoQ1 Química.

15 - Quais os pontos positivos e negativos do FoQ1 Química?

16 - O que você mudaria FoQ1 Química?

17 - Espaço para observações não contempladas pelas questões anteriores:

Quadro 1 - Questionário

Fonte: Elaborado pelos autores (2020).

O questionário avaliativo foi elaborado no formulário do Google e disponibilizado online via Google Sala de Aula e grupos de WhatsApp, onde os estudantes responderam ao questionário avaliativo. A escolha da aplicação do questionário avaliativo on-line possibilitou maior agilidade de respostas, além de atingir um público bem maior de forma segura e principalmente tendo a tabulação realizada em imediato (CALLIYERIS; LAS CASAS, 2016). Ademais, a escolha dos questionários on-line se deu principalmente devido ao período de desenvolvimento da pesquisa, em que as aulas presenciais estavam suspensas por causa da pandemia do novo coronavírus (PARAÍBA, 2020a).

A terceira etapa da pesquisa foi a realização de uma entrevista não-diretiva com intuito de aprofundar a avalição dos estudantes em relação ao FoQ1 Química (Quadro 2).

Qual a sua avaliação em relação ao aplicativo FoQ1 Química?

Por qual motivo considera essa avaliação?

Você recomendaria esse aplicativo para um colega? Por que?

Poderia justifica suas respostas ao itens da questão 14 do questionário avaliativo?

Como você avalia a utilidade do aplicativo FoQ1 Química nos estudos de Química.

Como você avalia a utilidade do aplicativo FoQ1 Química nos estudos de fórmulas, equações e modelos matemáticos aplicados na Química.

Como você avalia o conteúdo do FoQ1 Química.

Como você classifica sua perícia para compreensão dos fenômenos químicos após uso do FoQ1 Química.

Como você classifica sua perícia para compreensão dos conceitos químicos após uso do FoQ1 Química.

Como você classifica sua perícia para realização de cálculos na Química após uso do FoQ1 Química.

Para estudantes que deram respostas positivas Para estudantes que deram respostas negativas em relação ao aplicativo.

Quer dizer que acredita na utilização do aplicativo nos seus estudos de Química? Por que?

Então você não mudaria nada no aplicativo?

\section{em relação ao aplicativo.}

Quer dizer que não acredita na utilização do aplicativo nos seus estudos de Química? Por quer? Isso quer dizer que mudaria algo no aplicativo?

Quadro 2 - Perguntas guias da entrevista

Fonte: Elaborado pelos autores (2020).

A entrevista foi aplicada a uma amostra de $10 \%$ da parcela dos estudantes que participaram do questionário avaliativo, que afirmaram ter baixado o FoQ1 Química (Questão 
4). Metade dessa amostra apontou uma classificação positiva (MUITO BOM ou BOM) e a outra metade fez classificação negativa (MUITO RUIM OU RUIM) nos seis (6) itens (Questão 14) que indagavam sobre a utilidade do app nos estudos de Química (nos estudos de FEMAQ, sobre o conteúdo de FEMAQ no FoQ1 Química). As entrevistas foram agendadas pelas redes sociais (WhatsApp ou Instagram), realizadas através do Google Meet e gravadas com Movavi Screen Record 11 para registrar o momento e facilitar a análise posteriormente.

A quarta etapa consistiu na análise das respostas do questionário avaliativo aplicado na segunda etapa e da entrevista não diretiva realizado na terceira etapa. Esta etapa possibilitou organizar os dados e expor as informações estatísticas de maneira concisa e atentando-se para as argumentações qualificadas nas quais representavam objetividade relevante sobre FoQ1 Química e seu uso (GERHARDT; SILVEIRA, 2009). Esta análise ainda foi caracterizada pelas especificidades dos diálogos nas entrevistas dando maior caracterização e personificação aos dados. Como explicam Britto Júnior e Feres Júnior (2011, p. 241) “a entrevista pode desempenhar um papel vital para um trabalho científico se combinada com outros métodos de coleta de dados, intuições e percepções provindas".

Ao final das etapas, realizou-se a síntese de todos os dados obtidos, que foram expostos em tabelas, quadros, figuras, gráficos e textos, de forma a construir um relatório dissertativo dessas informações, demonstrando os elementos que configuram as percepções dos estudantes sobre a temática, seguindo uma exposição reflexiva e descritiva de cada ponto abordado (BONI; QUARESMA, 2005). Para manter o anonimato dos estudantes, optou-se por identifica-los da seguinte forma: no questionário avaliativo apresentamos a sigla EXX, em que E significa Estudante e XX o número atribuído ao estudante, sendo o intervalo de 01 a 75 . Na entrevista identificamos os estudantes como "Estudante A", "Estudante B", ..., "Estudante F".

\section{ANÁLISES E RESULTADOS}

A avaliação do FoQ1 Química foi realizada por 75 estudantes do ensino médio (sendo 50 do primeiro ano e 25 do segundo ano). As primeiras questões da avaliação buscaram caracterizar aspectos das aulas à distância, que estavam ocorrendo devido a pandemia do novo coronavírus. Nesta demanda a maior parte indicou que "Sim" (92\%), ou seja, que estão participando de alguma atividade de ensino e aprendizagem à distância. Consideramos este número representativo, indicando que a maior parte dos estudantes está dando continuidade aos estudos, mesmo diante da suspensão das aulas presenciais e da migração para atividades não 
presenciais. Porém, é importante atentar-se para o fato de haver uma parcela de estudantes que não está participando das atividades virtuais, mesmo tendo acesso à internet $\mathrm{e}$ aos canais de estudos, o que pode indicar uma resistência à modalidade ou à metodologia que vem sendo desenvolvida. Sabe-se que há, também, estudantes que não têm recursos ou dispositivos para participarem das aulas virtuais.

$\mathrm{Na}$ segunda questão, objetivou-se identificar quais as plataformas estavam sendo utilizadas para os estudos virtuais. Nessa pergunta eles poderiam apontar mais de um item (se fosse o caso). As respostas identificaram que o Google Sala de Aula foi a plataforma mais usada (98,60\%), seguindo pelo Whatsapp (42\%) Instagram (15,47\%), Google Meet (7,20\%), Facebook (2,80\%), Moodle (1,40\%) e Zoom (1,40\%). A superioridade do Google Sala de Aula pode ser justificada devido a recomendação da Secretária Estadual de Educação Ciências e Tecnologia da Paraíba (SEECT - PB), ou seja, foi um recurso acionado pela própria secretária de educação para suprir a demanda devido a suspensão das aulas presenciais. Todavia, os professores e estudantes recorreram a outros recursos para os estudos, inclusive redes sociais, indicando autonomia dos professores e estudantes em superar as dificuldades de um período de exceção provocado pelo isolamento social. Essa diversificação de recursos é uma demonstração de que houve a busca de vias para adaptar o processo de ensino e aprendizagem (COUTO; COUTO; CRUZ, 2020), pois esta diversificação é uma demonstração das tentativas de estabelecer comunicação entre professores e estudantes para processo educacional.

A questão três solicitava a classificação de dois itens em "Muito Ruim", "Ruim", "Regular", "Bom" e "Muito Bom". No primeiro item, "como você avalia esse mecanismo de ensino diante da atual situação do isolamento social", a maioria dos estudantes pesquisados $(43,5 \%)$ avaliou como "Regular", outra parcela (30\%) classificou como "Bom" e uma pequena parcela $(4,3 \%)$ considerou "Muito Bom". Isto pode indicar que as plataformas ainda sofrem resistência por parte dos estudantes, mesmo em um momento de necessidade de seu uso ou falta de capacitação para uso destes. No segundo item $36 \%$ dos estudantes avaliaram como "Bom" e 29\% como "Regular", afirmando que "as plataformas são fáceis e consigo aprender com elas", o que denota que elas podem ser mais uma alternativa para o processo de ensino e aprendizagem (TORI, 2017).

Apesar dessa indicação positiva, foi observado uma parcela de 11,6\% dos estudantes que classificou como "Muito Ruim" e 23,2\% "Ruim", o que pode indicar que os estudantes ainda têm ressalvas sobre o uso dessas plataformas. Essas ressalvas podem ser influenciadas por diversos fatores, como, o tempo de uso das plataformas, objetivo e metodologias 
desenvolvidas nelas. Porém, esse posicionamento negativo das plataformas de ensino não desclassifica o seu uso no processo de ensino, já que são recursos auxiliares e não a fonte única e principal para construção do saber.

A partir da questão quatro, as perguntas foram específicas sobre o FoQ1 Química. Primeiramente, indagou-se quem fez o download do app. Nesta questão $75 \%$ dos estudantes pesquisados baixaram o app. Um número expressivo, mas que poderia ter alcançado mais estudantes tendo em vista que o professor da disciplina solicitou que baixassem para poder trabalhar os conteúdos da Química com o auxílio do app. Entre os $25 \%$ que não baixaram o FoQ1 Química, 5\% tiveram acesso ao material do app via $P D F$ (Resposta a Questão 5), o que implica dizer que 20\% dos pesquisados não obtiveram acesso à informações do FoQ1 Química de nenhuma maneira, o que foi ponto impremeditável, porém não afetou o andamento da avaliação, pois os estudantes que baixaram ou tiveram acesso ao material do FoQ1 Química representam uma amostra significativa para a proposta metodológica dessa pesquisa.

Na sexta questão a parcela de estudantes que não baixou o FoQ1 Química, justificou essa ação. Para 66\%, a justificativa de não terem baixado o aplicativo estava ligado à questão da memória do aparelho celular (espaço para armazenamento), apesar do FoQ1 Química ocupar pouco espaço $(9,1 \mathrm{MB})$, ou seja, isso pode indicar que os celulares dos estudantes não apresentam muita memória (ou tem diversos aplicativos que ocupam o espaço disponível do aparelho). Outra parcela (13\%) indicou não ter interesse na disciplina de Química, por isso não baixaram o aplicativo relacionado à disciplina, fato preocupante e que inspira a busca de recursos e metodologias que engajem esses estudantes. Os demais (21\%) afirmaram não ter conseguido baixar o FoQ1 Química, porém essas últimas respostas, visivelmente, são inconsistentes, pois o app se encontra disponível na loja da Google Play que é específica para dispositivos com sistema Android. Após análise dessa questão, foram realizados testes controlados de download do FoQ1 Química e não encontramos nenhum problema, o que evidencia inconsistência nessas respostas.

Ao serem questionados se utilizam outros apps para estudos (questão sete), e sendo a resposta positiva, deveriam informar quais seriam esses apps (Questão 8). Observa-se que a maioria (56\%) dos estudantes não fazia uso de outros aplicativos para estudos, o que por um lado surpreende, visto que há inúmeros aplicativos que podem ser usados para esse fim. Entre os estudantes que usam outros aplicativos para estudo (44\%), foram relacionados os seguintes: Youtube, Studos, Descomplica, Duoling, Google Livros, Google Tradutor, Brainlyn e RevisApp. O número pequeno de apps (apenas oito) que estes estudantes utilizam para estudos evidencia 
um campo aberto para exploração do uso de apps, contudo necessita de propostas para melhorar as condições e percepções do tema entre os participantes.

Para dar maior conformidade ao uso de apps pelos os estudos, na questão nove (9) foi solicitado que eles avaliassem o uso de seus apps de estudos (identificados anteriormente na Questão 8) em uma escala de "Muito Ruim", "Ruim", "Regular", "Bom" e "Muito Bom". Respectivamente, foi identificado $2,7 \%, 13,3 \%, 41,3 \%, 34,7 \%$ e $8 \%$, revelando uma visão heterogênea sobre os aplicativos para estudos próprios. São resultados promissores, apesar de a maioria classificar o uso como "Regular" (41,3\%), a porcentagem que indica "Bom" (34,7\%) ou "Muito Bom" (8\%) somados sugere indicativos positivos, garantido que os apps podem (e devem) ser usados para estudos, porém é preciso refletir que estratégias podem ser utilizadas para contribuir com o processo de ensino e aprendizagem.

Os estudantes foram indagados se conheciam algum aplicativo com a mesma temática do FoQ1 Química (Questão 10). Nesse item, 16\% indicaram conhecer um app com a mesma proposta do FoQ1 Química, já na pergunta seguinte (Questão 11) todos os 16\% indicaram o mesmo app "Formula Química", mostrando que há uma demanda para esta temática (ou seja, só existem dois aplicativos).

Dentro desse contexto, questionamos os estudantes se haviam usado o FoQ1 Química para estudo (Questão 12), identificando que 65\% afirmaram que "Sim", o que viabiliza a sua utilização como um recurso para processo educacional. Embora, o percentual de estudantes que não fez uso do app (35\%) seja representativo, considera-se um resultado aceitável e positivo (o número dos que fizeram uso) ao comparar com os números de estudantes que fazem uso de outros aplicativos para estudo (Questão 7 - que foi apenas 44\%), ou seja, há uma significativa representatividade numérica de que o FoQ1 Química pode ser um recurso auxiliar para o processo de ensino e aprendizagem. Os estudantes que não fizeram uso do app (35\%) justificaram sua resposta (Questão 13) sendo bastantes sinceros em suas respostas: "por que não quis" (15\%), "não sabia que ele servia para estudar" $(10 \%)$, "não tive oportunidade para estudar com o aplicativo" (8\%) e "por que não achei necessário" $(2 \%)$. Por se tratar de uma pergunta subjetiva, esperava-se respostas distintas, indicando pensamentos diferentes sobre o tema.

Ponderando ainda sobre os motivos de não utilizarem o FoQ1 Química nos estudos, temos um prisma complexo. No primeiro ponto, analisou-se as respostas dos estudantes que falaram “ por que não quis", o que pode indicar falta de afinidade com a disciplina de Química ou até mesmo com o uso de app para estudos. No segundo ponto, observou-se nas respostas 
dos estudantes que afirmaram "não sabia que ele servia para estudar" um feedback inesperado, porque essa informação (que o app é para estudo de FEMAQ) está disposta na primeira página FoQ1 Química, como nas páginas seguintes também. Além de que, as informações referentes ao aplicativo foram apresentadas através das aulas de Química, o que dava o indicativo de seu objetivo. Consideramos que essas respostas ficam inócuas, pois retratam uma falta de atenção ao app e de leitura de suas informações. No terceiro ponto, examinou as respostas que diziam "não tive oportunidade para estudar com o aplicativo", justificativa plausível, pois com a pandemia as rotinas mudaram e nem sempre dá para cumprir o planejamento de estudo. Quarto ponto "por que não achei necessário" pode indicar que os estudantes já estejam em nível de aprendizado que desconsidere o auxílio do FoQ1 Química, ou que não se sentiram atraídos ao uso do aplicativo para estudos.

Na questão 14, foi solicitado a classificação em série de seis (6) itens relacionados ao uso do FoQ1 Química em "Muito Ruim”, "Ruim”, "Regular”, “Bom” e "Muito Bom”. A partir disso, buscamos expor um delineamento que possibilitasse o melhor entendimento sobre as percepções dos estudantes em relação ao FoQ1 Química. No primeiro item (Questão 14) questionou-se "como os estudantes avaliavam a utilidade do aplicativo FoQ1 Química nos estudos de Química”, cujos resultados foram considerados promissores (Gráfico 1).

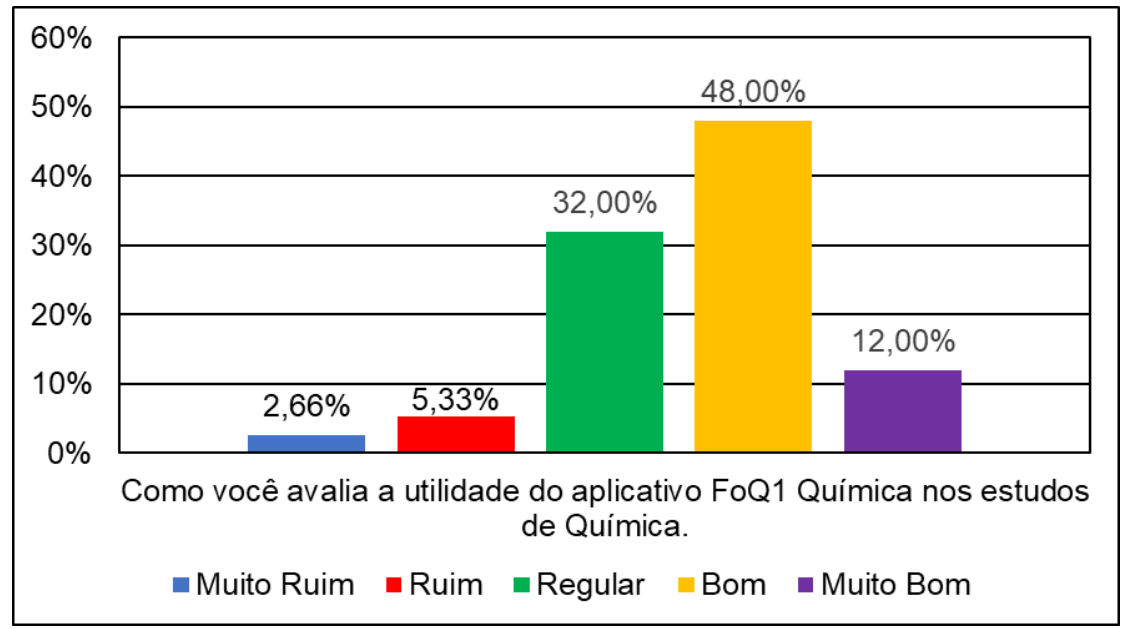

Gráfico 1 - Avaliação da utilidade do FoQ1 Química nos estudos de Química Fonte: Elaborado pelos autores (2020).

Os dados apresentados no Gráfico 1 mostram uma avaliação favorável em que 48\% dos estudantes classificaram como "Bom" e 12\% como "Muito Bom", ultrapassando mais da metade da amostra (60\%). Isto revela grande significância, por ser um percentual bem acima da "avaliação do uso de aplicativos para estudo" ("Bom" - 34,7\% e "Muito Bom" - 8\%). Além disso, as indicações de "Muito Ruim" e "Ruim" foram significativamente baixas, 2,7\% e 5,3\%, 
respectivamente, justificando que a avaliação do FoQ1 Química o postula como útil para o estudo de FEMAQ, na visão dos principais interessados, os estudantes. Essa idealização é notadamente corroborada pelas respostas do segundo item (Questão 14) - "como você avalia a utilidade do aplicativo FoQ1 Química nos estudos de fórmulas, equações e modelos matemáticos aplicados na Química" e terceiro item (Questão 14) - "como você avalia o conteúdo do FoQ1 Química", que traz dados similares (Gráfico 2), indicando que o app o FoQ1 Química pode ser classificado como categoria relevante de material pedagógico.

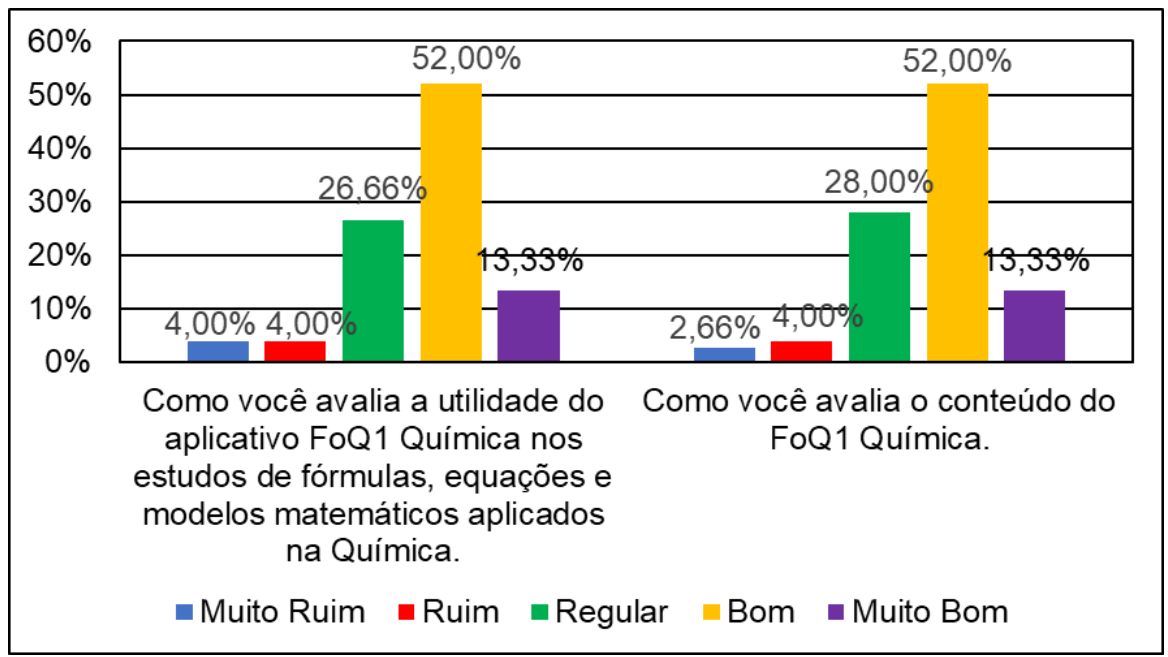

Gráfico 2 - Avaliação da utilidade do FoQ1 Química nos estudos de FEMAQ e Avaliação do conteúdo do FoQ1 Química

Fonte: Elaborado pelos autores (2020).

Como pode ser observado no Gráfico 2, o FoQ1 Química teve uma avalição positiva nos estudos FEMAQ, como demonstram os números: (4\%) "Muito Ruim", (4\%) "Ruim", (26,66\%) "Regular", (52\%) "Bom" e (13,33\%) "Muito Bom". Assim como nos dados da avaliação do conteúdo do app: (2,66\%) "Muito Ruim”, (4\%) “Ruim”, (28\%) "Regular”, (52\%) "Bom" e (13,33\%) "Muito Bom". Essas respostas podem indicar as qualidades do FoQ1 Química como material para estudos. Todavia, o mais expressivo é que a avaliação dos estudantes, apontam que há uma demanda na área, que pode ser preenchida pelo app, dando suporte para construção do conhecimento Químico de forma sólida. No entanto, não se pode desconsiderar a parcela que faz avalição como "Regular" no Gráfico 2, pois tem níveis profusos, alertando para que haja ponderações sobre o app e corrija pontos que ponham em dúvida sua utilidade, mas lembrando que nenhum recurso pedagógico irá suprir todas as necessidades apresentadas pelos envolvidos no processo educacional, pois os sujeitos podem aprender por caminhos distintos (GENTILE, 2015). 
Ainda se observa que esses recursos (apps) não têm objetivo de substituir o professor, e sim, ser mais um canal para colaborar no processo, tanto de ensino, como de aprendizagem, portanto devendo estar presentes nos cursos de formação de professores (CARVALHO, 2018), de modo que estes (professores) possam ser munidos de conhecimentos e informações para poderem fazer o melhor uso possível das tecnologias digitais, pois caso contrário (suas ações) não surtirão efeitos positivos no processo de aprendizagem na Química.

Na sequência, apresenta-se a classificação do item quatro (Questão 14) que questionou “como o estudante classificava sua capacidade para compreensão dos fenômenos químicos após uso do FoQ1 Química”. Os resultados revelam dados positivos, apesar do aumento substancial na avaliação como "Regular", não destoa incisivamente dos dados positivos ("Bom” e "Muito Bom”), pois sua somatória continua ultrapassando 50\% da amostra (Gráfico 3).

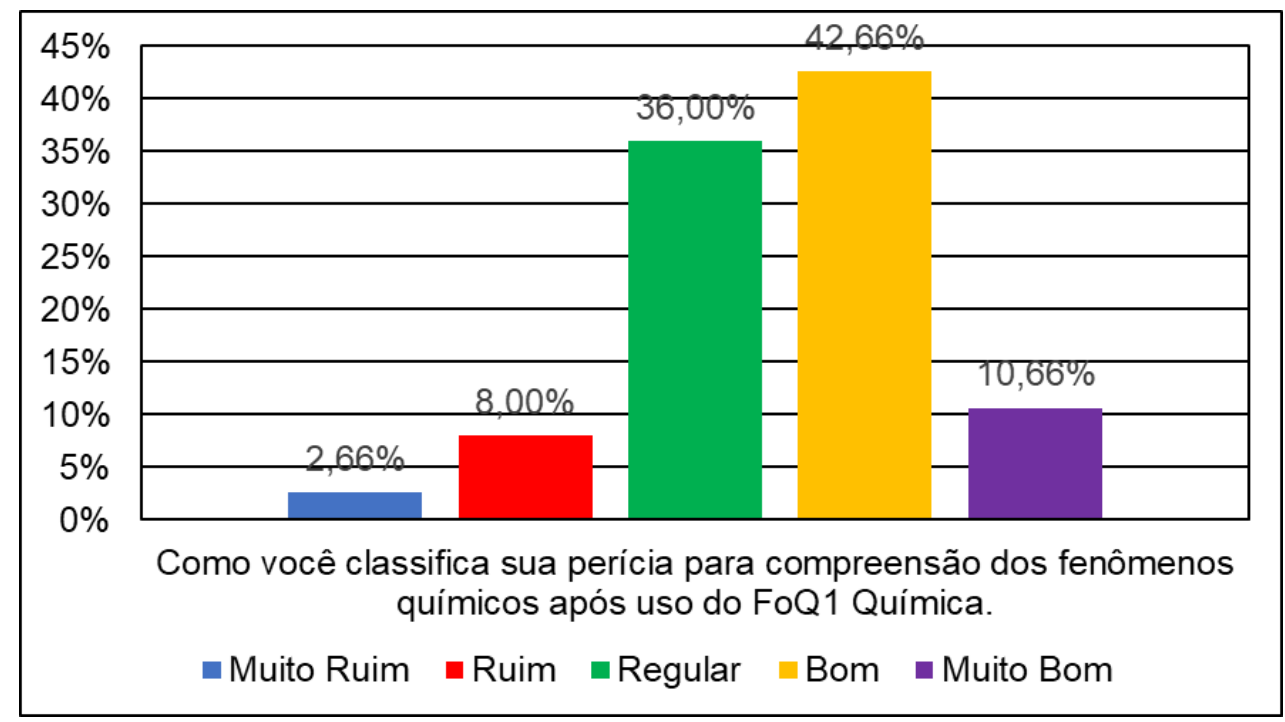

Gráfico 3 - Capacidade aos fenômenos Químicos após uso do FoQ1 Química Fonte: Elaborado pelos autores (2020).

Os dados revelados no Gráfico 3 deixam explícitos como os estudantes acreditam na boa avaliação do FoQ1 Química. Isto pode indicar que o app pode corroborar no processo de aprendizagem da Química, influenciando nos estudos dos fenômenos químicos. Esses dados reforçam o já encontrado na literatura (SANTANA, 2016; BARBOZA, 2016) transparecendo que a Matemática é um pilar para o estudo de Química, pois ajuda na interpretação e representação, além de estar intrínseca à ideia da contextualização e da interdisciplinaridade, que é a base do FoQ1 Química em relação às FEMAQ. Dessa mesma forma, o entendimento sobre os conceitos Químicos tem uma relação com a Matemática e consequentemente com as FEMAQ (PREDOSA; MAFRA; SIQUEIRA, 2015; BARBOZA, 2016). 
No item cinco da questão 14 , buscou exatamente tratar da relação do uso do FoQ1 Química com os conceitos químicos. Os dados (Gráfico 4) revelam que a impressão positiva ("Bom" e "Muito Bom") continua sendo superior à negativa ("Muito Ruim" e "Ruim"). Isso pode significar que os estudantes ao utilizarem o FoQ1 Química, conseguiram compreender melhor sobre fenômenos químicos do que os conceitos químicos, tornando-se um ponto observável que demande reflexão sobre o uso do app (FoQ1 Química), já que parte do conhecimento de Química aplicado no ensino médio é alicerçado por conceitos.

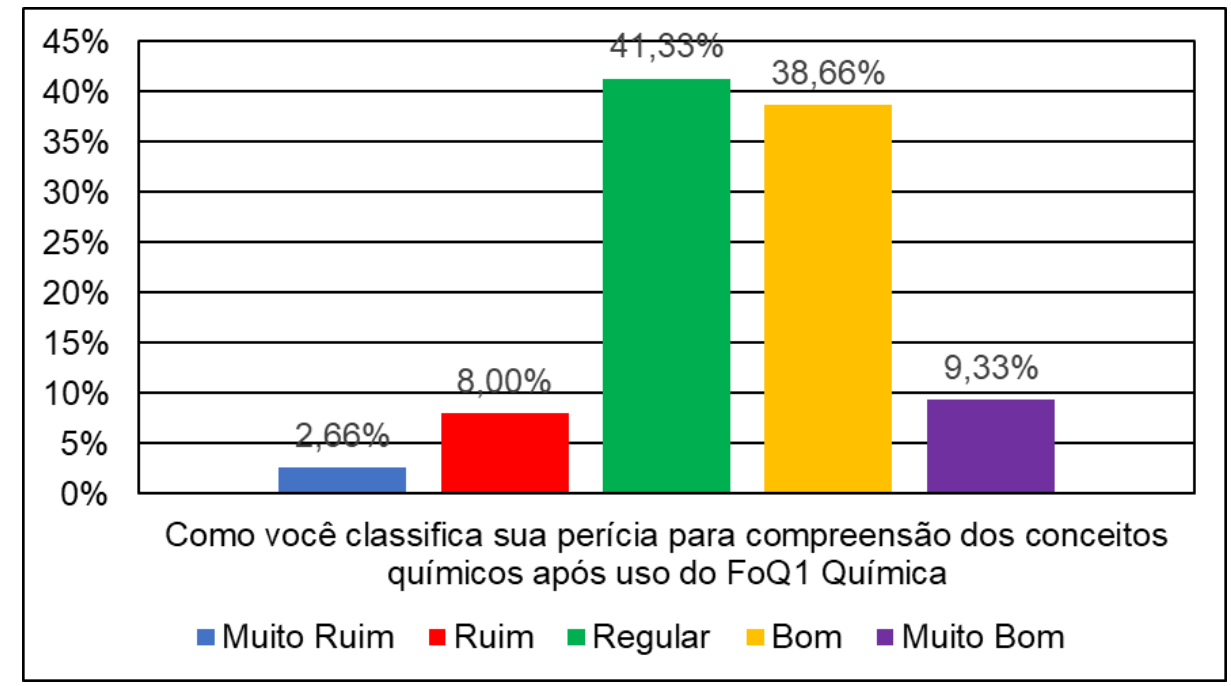

Gráfico 4 - Aptidão aos conceitos químicos após uso do FoQ1 Química Fonte: Elaborado pelos autores (2020).

Como exposto no Gráfico 4, a maioria dos estudantes $(41,33 \%)$ classificou como "Regular" a compreensão dos conceitos químicos após o uso do app, e isso leva a conjecturar que a formação de conceito químico, a partir dos estudos no aplicativo, não ficaram claros, mas uma parcela indicava como "Bom" (38,66\%) e "Muito Bom" (9,33\%), inferindo que o problema pode não ser o FoQ1 Química. Contudo, ratifica-se, mais uma vez, que nenhum recurso para o ensino é suficiente para suprir a demanda de todos os estudantes. Em outros termos, o FoQ1 Química pode ser produtivo para a construção do conhecimento químico de alguns estudantes, mas não entre todos.

No último item desta série (Questão 14), a classificação era em relação à capacidade para realização de cálculos na Química após utilizarem FoQ1 Química. E como o app trata diretamente das FEMAQ, esses dados obtidos a partir das respostas dos estudantes foram significativos para compreendermos melhor qual o impacto do app no que diz respeito à resolução de cálculos matemáticos, como pode ser observado no Gráfico 5. 


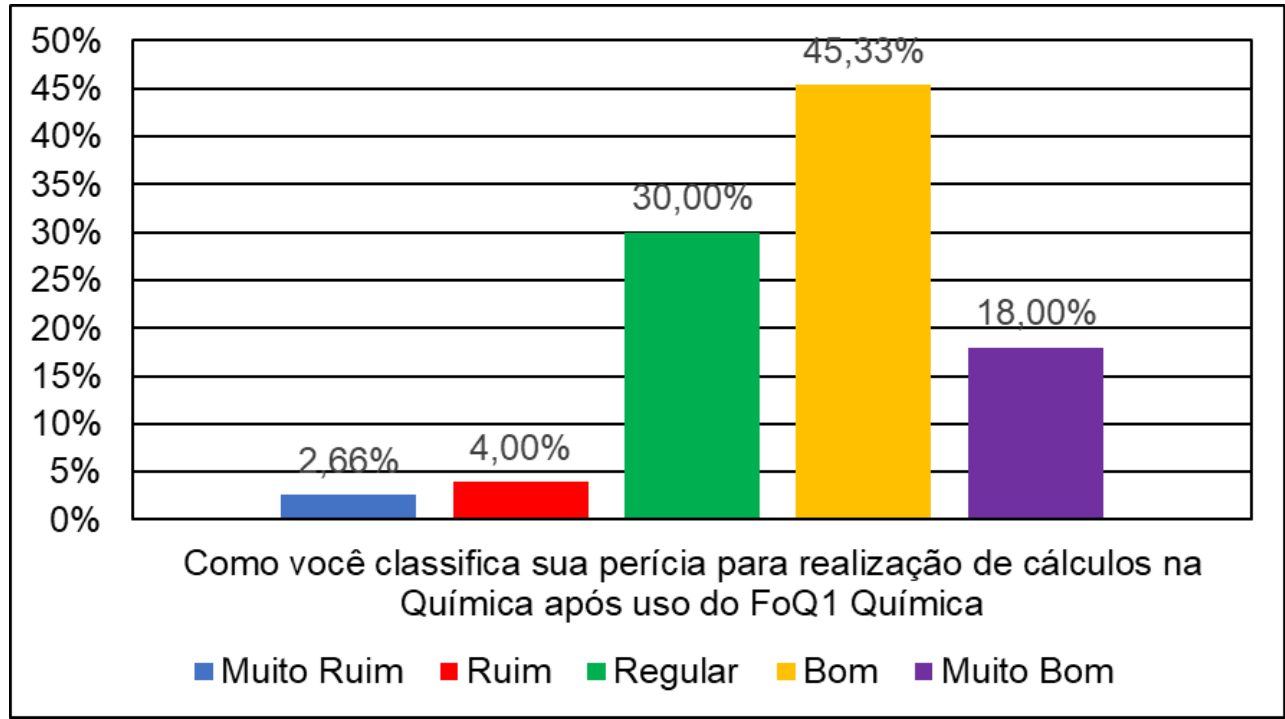

Gráfico 5 - Capacidade de realizar cálculos de Química após o uso do FoQ1 Química Fonte: Elaborado pelos autores (2020).

As respostas do sexto item ficaram entre os melhores resultados (Gráfico 5) da série de classificação (Questão 14): "Muito Ruim" 2,66\%, "Ruim" 4\%, "Regular" 30\%, "Bom” 45,33\% e "Muito Bom" 18\%. Isto sugere que o FoQ1 Química teve boa aceitação dos estudantes sobre o principal objetivo do app, que é auxiliar na aprendizagem das FEMAQ. Importante que a avaliação positiva deste item eleva os status do app, referendando a ideia da necessidade de estudos e desenvolvimento de recursos para estudos das FEMAQ. Mesmo com números apontando para as boas qualidades do FoQ1 Química, não se pode ignorar a parcela que indicava pontos negativos ("Muito Ruim" e "Ruim") e muito menos os meios-termos ("Regular"), em outras palavras termos, fica evidente que há uma falta de unidade sobre o estudo da Química, havendo necessidade de desenvolvimento de recursos e estratégias para diminuir as disparidades em relação a construção do conhecimento químico, tendo em vista que está ação é um dever social, político e econômico (NEVES; BRAGUINI, 2018).

Para corroborar com as classificações da série de seis itens da questão 14 do questionário avaliativo e descrever com mais detalhes as impressões dos estudantes, foi solicitado que apontassem os aspectos positivos e negativos em relação ao FoQ1 Química (Questão 15). Os resultados seguem no Quadro 3, apresentamos a transcrição de alguns comentários dos estudantes. 


\begin{tabular}{|c|c|c|}
\hline Estudante participante & Aspectos positivos & Aspectos negativos \\
\hline Estudante 10 & $\begin{array}{l}\text { É resumido, fácil de usar, atua diretamente no que } \\
\text { preciso agora no ensino médio. }\end{array}$ & $\begin{array}{l}\text { Poderia ter atividades } \\
\text { ou vídeos. }\end{array}$ \\
\hline Estudante 11 & $\begin{array}{l}\text { Ele é diferente dos outros aplicativos que conheço } \\
\text { não tem distração. }\end{array}$ & $\begin{array}{l}\text { Muito resumido os } \\
\text { conteúdos. }\end{array}$ \\
\hline Estudante 12 & $\begin{array}{l}\text { Atende minhas necessidades básicas, simples, } \\
\text { direto e descomplicado. }\end{array}$ & $\begin{array}{l}\text { Deveria ter outros } \\
\text { temas. }\end{array}$ \\
\hline Estudante 13 & $\begin{array}{l}\text { Ele é direto, não tem arrodeio, ajuda nas nossas } \\
\text { dificuldades. }\end{array}$ & $\begin{array}{l}\text { Que não pode } \\
\text { pesquisar. }\end{array}$ \\
\hline Estudante 14 & Ele é resumido, o que ajuda muito, não enrola. & Tem poucos temas. \\
\hline
\end{tabular}

Quadro 3 - Aspectos positivos e negativos do FoQ1 Química

Fonte: Elaborado pelos autores (2020).

As transcrições dos comentários dos estudantes trazem um reflexo do antagonismo das respostas com os identificados nos itens da questão 14 do questionário avaliativo, demonstrando um confronto entre as interpretações sobre o FoQ1 Química e sua aplicação ao estudo de Química, porém esta diferença de ideias é um fato natural, pois os sujeitos têm visões e compreensões de mundo diferentes, com aprendizagem instintivas, o que pode revelar ideias diferentes sobre o mesmo tema (POZO, 2008). Esse raciocínio fica claro nos discursos dos aspectos positivos (Estudante 14) e negativos (Estudante 11) quando eles afirmam:

“Ele é resumido, o que ajuda muito, não enrola” (Resposta do estudante 14, 2020);

"Muito resumido os conteúdos" (Resposta do estudante 11, 2020).

A fala dos estudantes expressam uma divergência do que é positivo e negativo no FoQ1 Química, porém, falando da mesma característica, o que ratifica a alegação de que nenhum recurso didático pedagógico atenderá as necessidades e interesse de todos os sujeitos. Por tanto, na observação dos aspectos do app, é importante destacar que um grupo de estudantes (35\%) não indicou nenhum aspecto positivo ou negativo. Analisando os aspectos negativos indicados, pode-se compreender que algumas das citações, apesar de apontadas como negativas, na realidade são características que o FoQ1 Química vem tentando suprir, como abordar temas apenas do primeiro ano do ensino médio que envolveram as FEMAQ; ser objetivo e incisivo; que pudesse ser democrático e acessível fornecendo conteúdo off-line através do aplicativo, mas também em $P D F$. No entanto, é necessário destacar que essas indicações dos estudantes devem ser levadas em consideração para que sejam atendidas em outros recursos pedagógicos, mas que foque na temática FEMAQ.

Por fim, os estudantes foram questionados (Questão 16) sobre qual mudança eles fariam no app, cuja Tabela 1 apresenta as sugestões. 


\begin{tabular}{l|c}
\multicolumn{2}{c}{ Tabela 1 - Sugestões para o FoQ1 Química } \\
\hline \multicolumn{1}{c}{ Sugestões } & Porcentagens \\
\hline Colocaria Física e Matemática. & $17,33 \%$ \\
$\begin{array}{l}\text { Colocaria alguns vídeos explicativos (tipo vídeo aula), e algumas } \\
\text { imagens relacionadas às fórmulas e os assuntos para que } \\
\text { possamos compreender melhor. }\end{array}$ & $1,33 \%$ \\
$\begin{array}{l}\text { Mudaria o design do aplicativo, para um mais interativo, com } \\
\text { cores combinadas que chamem a atenção. }\end{array}$ & $1,33 \%$ \\
Colocaria outras matérias desse jeito, simples e bem direto. & $10 \%$ \\
Acrescentaria alguma ferramenta de pesquisa. & $14 \%$ \\
Deixaria parecido com plataforma studos. & $10 \%$ \\
Mudaria o nome pois acho meio confuso. & $4 \%$ \\
\hline
\end{tabular}

Fonte: Elaborado pelos autores (2020).

Como pode ser verificado na Tabela 1, as repostas seguiram um padrão, com feedbacks idênticas mesmo sendo uma questão subjetiva que poderia expressar particularidades já que cada estudante deveria manifestar suas próprias apreensões sobre os aspectos abordados no app . Além do já descrito, cerca de $30 \%$ afirmaram que não mudariam nada no aplicativo, e $12 \%$ disseram não saber sugerir nada. Essa questão traz grande representatividade, primeiro porque exibe as impressões dos estudantes sobre um app para estudos, segundo por indicar que o FoQ1 Química segue uma linha importante de estudos, já que parte considerável das sugestões $(17,33 \%)$ manifestou aspiração de incluir a Física e a Matemática ao app, ou seja, a forma como o FoQ1 Química tratou a temática de fórmulas e cálculos pode ser transposta para outras disciplinas. Esse mesmo raciocínio fica evidente na colocação do Estudante 20 ao dizer que:

“Colocaria outras matérias desse jeito, simples bem direto” (Resposta do estudante 20, 2020).

Outras sugestões inferidas pelos estudantes ultrapassam o objetivo do app, como incluir vídeo aulas, apesar de ser uma sugestão que possa contribuir para construção do conhecimento Químico, pois poderia limitar o uso do FoQ1 Química como o seu funcionamento off-line ou sua capacidade de ocupar pouco espaço na memória. As demais sugestões relacionadas ao layout, design, comandos e nome do app, podem ser convenientes, mas essas ideais variam de acordo com a visão de cada sujeito, ou seja, uma estratégia de mercado que nem sempre consegue atingir todo seu público-alvo.

Na última pergunta do questionário avaliativo foi aberto um espaço para considerações finais, mais um momento subjetivo, mas infelizmente esta questão foi deixada sem resposta por todos os participantes, evidenciando a conclusão dessa etapa da pesquisa. A falta de considerações finais pode indicar que o questionário avaliativo contemplou todos os aspectos 
que poderiam ser aferidos pelos estudantes. Nesse contexto, a pesquisa continuou com a análise das entrevistas, dando ênfase às ideias e observações dos estudantes em relação ao FoQ1 Química, sendo descritos na próxima seção.

\subsection{Entrevistas}

Foram entrevistados 6 estudantes, cerca de $10 \%$ do total de alunos que utilizou o FoQ1 Química. Deste grupo de estudantes selecionados para entrevista, 50\% apreciaram positivamente o aplicativo, e os outros 50\% apresentaram sua avaliação caracterizando negativamente o app na série de classificação de seis (6) itens da questão 14 no questionário avaliativo.

As entrevistas potencializaram e ratificaram as discussões anteriores: primeiro nos aspectos negativos, os estudantes indicaram que o app precisaria melhorar alguns pontos, como layout, colocar mais conteúdos, inclusive de outras disciplinas como Física e Matemática, e colocar vídeos explicando as fórmulas, como pode ser visto nas transcrições das falas dos estudantes:

\footnotetext{
"Na minha opinião o aplicativo não ajuda muito, só tem química [...] e aprendo mais em vídeo aulas" (Resposta do estudante A, 2020);

"Não sou bom em Química, mas se tivesse mais informações seria melhor, mudasse as cores, colocasse uns efeitos, o app ficaria melhor" (Resposta do estudante B, 2020);

"Eu mudaria as cores, colocaria umas imagens chamativas, conteúdos como soluções e termoquímica com animação, mas principalmente colocaria uns vídeos explicando as fórmulas" (Resposta do estudante C, 2020).
}

Essas afirmativas dão indícios de que FoQ1 Química não atendeu a uma parcela dos estudantes. Porém, esses estudantes não apresentam falhas nas estruturas do aplicativo ou que comprometa seu principal objetivo, isto é, que o app possa cooperar no processo de ensino e aprendizagem como um recurso auxiliar, fornecendo informações básicas para construção do conhecimento químico, sendo um guia de consulta dos conteúdos de Grandezas Físicas, Leis Ponderais, Representação Atômica, Modelos Quantitativos da Química, Comportamento Físico dos Sistemas Gasoso e Estequiometria, seja no sistema de ensino formal ou na busca autônoma do conhecimento químico. Esse argumento fica mais fundamentado a partir das falas dos estudantes que deram boa avaliação em relação ao FoQ1 Química: 


\begin{abstract}
"O aplicativo muito bom, já tinha procura algum que me ajudasse a aprender os cálculos, mas não tinha achado nenhum até então [...] muita coisa aprendemos na escola, mas quando estudo em casa preciso de auxílio" (Resposta do estudante D, 2020);

"Gostei do FoQ1 Química, principalmente porque ele é simples sem enrolação, posso estudar sozinho" (Resposta do estudante E, 2020);

"Nuca achei nada igual, ele (o app) é muito bom, conteúdo (Balanceamento) que já tinha tentado aprender e não conseguia, consegui com ele. Mas o melhor de tudo que não tem distrações, como atividades ou propagandas" (Resposta do estudante F, 2020).
\end{abstract}

Os aspectos descritos pelos estudantes nas entrevistas ratificaram os dados observados durante as análises do questionário avaliativo, em que foram encontradas ideias de vários gêneros e intepretações sobre o FoQ1 Química, o que pode acontecer sobre a avaliação de qualquer produto, recurso, método ou ação pedagógica, já que encontrar uma unidade no processo de educacional pode ser inadequado, haja vista que os sujeitos são diferentes (BARBOSA, 2015; SOUZA, 2020). Diante disto, fica implícito que o FoQ1 Química pode ser um recurso pedagógico que atenda uma parcela de sujeitos que se tenha afinidade com alguns aspectos da Química ou desejo de usar um aplicativo que funcione como um guia instrutivo para estudos de FEMAQ.

\title{
5 CONSIDERAÇÕES FINAIS
}

Esta pesquisa delineou as percepções dos estudantes sobre o aplicativo FoQ1 Química como um RDD, apontando-o como um recuso auxiliar no processo de ensino e aprendizagem de Química, em especial nas FEMAQ, como demostrado nas respostas dos estudantes, em que avaliaram positivamente o app, inclusive com as avaliações superiores a outros aplicativos que usavam para estudo.

Apesar de haver considerações para ajustes no FoQ1 Química, as características de democratização e disponibilidade dão uma personificação exclusiva, como a possibilidade de download de seu conteúdo. Além de ser um app com perfil coadjuvante, ou seja, com objetivo de auxiliar o professor, se apresenta como um aplicativo para dispositivo móvel simples e efetivo. Neste contexto, compreende-se que um app pode corroborar para o processo de ensino e aprendizagem, principalmente quando é desenvolvido para este fim (COSTA; DUQUEVIZ; PEDROZA, 2015).

Aspectos relacionados com a resistência de uma parcela dos estudantes ao uso das TDIC como plataformas de ensino à distância e também aos apps, evidenciam que não são somente as tecnologias que podem melhorar o ensino dos conteúdos de Química, sendo preciso que o professor entenda que a utilização de aplicativos é mais um dos recursos disponíveis para sua 
prática pedagógica, toda via, para que ocorra com maior rotina e efetividade, essa prática deve estar inserida nas formações dos professores.

Neste trabalho ficou claro que os estudantes têm dificuldades em certos conteúdos de Química e que a utilização de RDD pode ser uma via para solucionar essas dificuldades, mas que é importante estar analisando, debatendo e (re)construindo essas questões. Com isso esperase que ocorram novas análises sobre aplicação do FoQ1 Química, como também o desenvolvimento de novos recursos que abordem o mesmo tema e possam acrescentar artifícios que colaborem na construção do conhecimento Químico.

\section{REFERÊNCIAS}

ANDRÉ, Marli. O que é um estudo de caso qualitativo em educação?. Revista da FAEEBAEducação e Contemporaneidade, Salvador, v. 22, n. 40, p. 95-103, 2013. Disponível em: https://www.nelsonreyes.com.br/Marli\%20Andr\%C3\%A9.pdf. Acesso em: 20 out. 2019.

ARAÚJO, Edilânia Gomes de. O uso de aplicativos de celular como ferramenta de auxílio à aprendizagem em Química Orgânica no Ensino Médio. Trabalho de Conclusão de Curso (Graduação) - Universidade Estadual da Paraíba, Campina Grande, p. 40. 2016. Disponível em: http://dspace.bc.uepb.edu.br/jspui/handle/123456789/14301. Acesso em: 01 nov. 2019.

BARBOSA, Priscila de Sousa. Dificuldades de Aprendizagem. São Luiz: Uemanet, 29 p. 2015.

BARBOZA, Anne Karoline Assis. A (Inter) Relação da Matemática e a Química: uma visão pontual de alunos do $1^{\circ}$ ano do ensino médio. 2016. 35 f. Monografia (Especialização) Curso de Especialização em Ensino de Ciências e Matemática para Séries Finais: Ensino Fundamental - $6^{\circ}$ Ao $9^{\circ}$ Ano, Universidade Federal de Integração Latino-americano, Foz do Iguaçu, 2016. Disponível em:

https://dspace.unila.edu.br/bitstream/handle/123456789/1758/Monografia\%20final_Anne.pdf ? sequence $=1 \&$ isAllowed $=\mathrm{y}$. Acesso em: 10 out. 2019.

BEZERRA, Anselmo; SILVA, Carlos Eduardo Menezes da; SOARES, Fernando; SILVA, José Alexandre Menezes.. Fatores associados ao comportamento da população durante o isolamento social na pandemia de COVID-19. Ciência \& Saúde Coletiva, Rio de Janeiro, v. 25, p. 2411-2421, 2020. Disponível em:

https://www.scielosp.org/article/csc/2020.v25supp11/2411-2421/. Acesso em: 10 ago. 2020.

BONI, Valdete; QUARESMA, Sílvia Jurema. Aprendendo a entrevistar: como fazer entrevistas em Ciências Sociais. Em Tese, Florianópolis, v. 2, n. 1, p. 68-80, 2005. Disponível em: https://periodicos.ufsc.br/index.php/emtese/article/view/18027/16976. Acesso em: 12 dez. 2019.

BRITTO JÚNIOR, Álvaro Francisco de; FERES JÚNIOR, Nazir. A utilização da técnica da entrevista em trabalhos científicos. Revista Evidência, Araxá, v. 7, n. 7, p. 237-250, 2011. 
Disponível em: https://met2entrevista.webnode.pt/_files/200000032-64776656e5/200-752-1PB.pdf. Acesso em: 12 dez. 2019.

BRASIL, [Resolução nº 466 (2012)]. Resolução no 466 de 12 de dezembro de 2012. Brasília, DF. Ministério da Saúde, [2012]. Disponível em: https://bvsms.saude.gov.br/bvs/saudelegis/cns/2013/res0466 12 12 2012.html. Acesso em: 25 out. 2019.

CALLIYERIS, Vasiliki Evangelou; LAS CASAS, Alexandre Luzzi. A utilização do método de coleta de dados via internet na percepção dos executivos dos institutos de pesquisa de mercado atuantes no Brasil. Interações (Campo Grande), Campo Grande, v. 13, n. 1, 2016. Disponível em: https://www.scielo.br/scielo.php?pid=S151870122012000100002\&script=sci_arttext. Acesso em: 15 dez. 2019.

CARVALHAES, Ketheryne Ferreira. O uso de aplicativos gratuitos como recurso didático no ensino de Química. 2016. 20 f. Trabalho de Conclusão de Curso (Licenciatura em Química) - Universidade de Brasília, Brasília, 2016. Disponível em: https://bdm.unb.br/handle/10483/19688. Acesso em: 10 nov. 2019.

CARVALHO, Ana Amélia Amorim. Formação Docente na era da Mobilidade: metodologias e aplicativos para envolver os alunos rentabilizando os seus dispositivos móveis. Revista Tempos E Espaços Em Educação, v. 11, n. 01, p. 25-36, 2018. Disponível em: https://pontadelanca.revistas.ufs.br/index.php/revtee/article/view/10047/pdf. Acesso em: 22 dez. 2019.

COSTA, Sandra Regina Santana; DUQUEVIZ, Barbara Cristina; PEDROZA, Regina Lúcia Sucupira. Tecnologias Digitais como instrumentos mediadores da aprendizagem dos nativos digitais. Psicologia Escolar e Educacional, São Paulo, v. 19, n. 3, p. 603-610, 2015. Disponível em: https://www.scielo.br/pdf/pee/v19n3/2175-3539-pee-19-03-00603. Acesso em: 13 mai. 2020.

COUTO, Edvaldo Souza; COUTO, Edilece Souza; CRUZ, Ingrid de Magalhães Porto. \#Fiqueemcasa: educação na pandemia da covid-19. Interfaces Científicas-Educação, Aracaju, v. 8, n. 3, p. 200-217, 2020. Disponível em: https://periodicos.set.edu.br/educacao/article/view/8777/3998. Acesso em: 12 ago. 2020

GENTILE, Fausto Rogério. Interdisciplinaridade: a essência humana para a sustentabilidade da educação? Interdisciplinaridade, São Paulo, n. 6, p. 37-43, 2015. Disponível em: https://revistas.pucsp.br/index.php/interdisciplinaridade/article/view/22626/16408. Acesso em: 03 jan. 2020.

GERHARDT, Tatiana Engel; SILVEIRA, Denise Tolfo (org.). Métodos de Pesquisa. Porto Alegre: Editora da UFRGS, 2009.

GONÇALVES, Ivanylson Honorio. Tutorial Google Meet. Juiz de Fora, 2020. Disponível em: https://www.ufjf.br/estatistica/files/2020/04/tutorial-GOOGLE-MEET-VERSION1.0.pdf. Acesso em: 13 ago. 2020.

GOUVEIA, Antônio Emilson Souza; PEREIRA, Elson de Menezes. O uso de tecnologia móvel: celular como apoio pedagógico na escola. Anais. II Colóquio de Letras da 
Fale/cumb-formação de professores: ensino, pesquisa, teoria. Breves-Pa, v. 4, n. 5, 2015. Disponível em: http://coloquiodeletras.ufpa.br/downloads/ii-coloquio/anais/41-antonioemilson.pdf. Acesso em: 10 nov. 2019.

KLEIN, Vanessa; SANTOS, Cassiano Vasconcelos; SOUZA, Darliana Mello. Aplicativos educacionais para o ensino de química: incidência e análise em trabalhos científicos. RedinRevista Educacional Interdisciplinar, Taquara, v. 7, n. 1, 2018. Disponível em: http://seer.faccat.br/index.php/redin/article/view/1057/641. Acesso em: 05 abr. 2020

LEITE, Bruno Silva. M-Learning: o uso de dispositivos móveis como ferramenta didática no Ensino de Química. Revista Brasileira de Informática na Educação, Porto Alegre, v. 22, n. 3, p. 55-68, 2014. Disponível em: https://www.brie.org/pub/index.php/rbie/article/view/2475/2832. Acesso em: 10 out. 2019.

LEITE, Bruno Silva. Tecnologias no Ensino de Química: teoria e prática na formação docente. Curitiba: Appris, 2015.

LEITE, Bruno. Silva. Aprendizagem Tecnológica Ativa. Revista Internacional de Educação Superior, Campinas, v. 4, n. 3, p. 580-609, 2018. Disponível em: https://periodicos.sbu.unicamp.br/ojs/index.php/riesup/article/view/8652160. Acesso em: 22 jan. 2020.

LOCATELLI, Aline; ZOCH, Alana Neto; TRENTIN, Marco Antonio Sandini. TICs no Ensino de Química: Um Recorte do "Estado da Arte". Revista Tecnologias na Educação, [S.1.] v. 12, n. 7, p. 1-12, 2015. Disponível em: http://tecedu.pro.br/wpcontent/uploads/2015/07/Art19-vol12-julho2015.pdf. Acesso em: 15 jan. 2020.

MACHADO, Adriano Silveira. Uso de softwares educacionais, objetos de aprendizagem e simulações no ensino de química. Revista Química Nova na Escola, São Paulo, v. 38, n. 2, p. 104-111, 2016. Disponível em: http://qnesc.sbq.org.br/online/qnesc38_2/03-QS-76-14.pdf. Acesso em: 11 nov. 2019.

MORAN, José. Tecnologias digitais para uma aprendizagem ativa e inovadora. In: MORAN, José. A Educação que Desejamos: novos desafios e como chegar lá. 5. ed. São Paulo: Papirus, p. 1-232. 2014.

MOREIRA, Uly Alves; DIEB, Messias. A relação de estudantes com a escolha do tema para seus projetos de pesquisa: mobilização e sentido para pesquisar. Revista Triângulo, Uberaba, v. 11, n. 3, 2018. Disponível em:

http://seer.uftm.edu.br/revistaeletronica/index.php/revistatriangulo/article/view/3093/3275.

Acesso em: 15 fev. 2020.

NEVES, Breno Gonçalves Bragatti; MELO, Rafaela da Silva. O Universo no bolso: tecnologias móveis de apoio didático-pedagógico para o ensino da Astronomia. RENOTERevista Novas Tecnologias na Educação, Porto Alegre, v. 12, n. 1, 2014. Disponível em: https://www.seer.ufrgs.br/renote/article/view/49827/31185. Acesso em: 20 fev. 2020.

NEVES, Késia Caroline Ramires; BRAGUINI, Maysa. A história da disciplina química (escolar) no currículo brasileiro. \# Tear: Revista de Educação, Ciência e Tecnologia, Porto 
Alegre, v. 7, n. 2, 2018. Disponível em:

https://www.periodicos.ifrs.edu.br/index.php/tear/article/view/3232. Acesso em: 21 jan. 2019.

NICHELE, Aline Grunewald; SCHLEMMER, Eliane. Aplicativos para o ensino e aprendizagem de Química. RENOTE, Porto Alegre, v. 12, n. 2, 2014. Disponível em: https://www.seer.ufrgs.br/renote/article/view/53497/33014. Acesso em: 25 mar. 2020.

PARAÍBA (Estado). Decreto $n^{\circ}$ 40.122, de 13 de março de 2020. João Pessoa, PB, Disponível em: https://auniao.pb.gov.br/servicos/arquivo-digital/doe/janeiro/marco/diario-oficial-14-032020.pdf/. Acesso em: 14 maio 2020.

PARAÍBA. GOVERNO DO ESTADO DA PARAÍBA. (org.). Notícias. Disponível em: https://paraiba.pb.gov.br/noticias. Acesso em: 14 maio 2020.

PASCHOARELLI, Luis Carlos; MEDOLA, Fausto Orsi; BONFIM, Gabriel Henrique Cruz. Características Qualitativas, Quantitativas e Qualiquantitativas de Abordagens Científicas: estudos de caso na subárea do design ergonômico. Revista de Design, Tecnologia e

Sociedade, Brasília, v. 1, n. 2, p. 65-78, jan. 2015. Disponível em:

http://periodicos.unb.br/index.php/design-tecnologia-

sociedade/article/download/15699/14030. Acesso em: 12 jun. 2020.

PREDOSA, Marcelo Sierpe; MAFRA, João Carlos Martins; SIQUEIRA, Angelo Santos. Uma proposta de modelagem matemática: prática de diluição contínua monitoradas por espectrofotometria visível na motivação do ensino de equações diferenciais para alunos de química. Revista de Educação, Ciências e Matemática, Duque de Caxias, v. 5, n. 1, 2015. Disponível em: http://publicacoes.unigranrio.edu.br/index.php/recm/article/view/2856/1381. Acesso em: 07 jun. 2020.

PEREIRA, Deydeby Illan dos Santos. Softweres Educacionais no Ensino de Química. 2014. 42 f. Monografia (Especialização) - Curso de Fundamentos da Educação, Universidade Estadual da Paraíba, Campina Grande, 2014. Disponível em: http://dspace.bc.uepb.edu.br/jspui/bitstream/123456789/13620/1/PDF\%20\%20Deydeby\%20Illan\%20dos\%20Santos\%20Pereira.pdf. Acesso em: 04 jun. 2020.

PEREIRA, Jocimario Alves; SILVA JÚNIOR, Jairo Ferreira da; SILVA, Everton Vieira da. Instagram como ferramenta de aprendizagem no ensino de química. REDEQUIM, Recife, v. 5, n. 1, p.119-131, jul. 2019. Disponível em:

http://www.journals.ufrpe.br/index.php/REDEQUIM/article/view/2099/482483054. Acesso em: 05 jul. 2019.

POSSA, André Dala; ACHUTTI, Camila; FERNANDEZ, Cassia; CALIXTO, Douglas; SCHADT, Felipe; ALBINO, Jacqueline Meneguel; TEIXEIRA, Marcelo Victor; ANTUNES, Michele Cristina Fonseca; SAITO, Ricardo Toshihito; COSTA, Suéller. Transliteracia na palma da mão: o smartphone na educação do século XXI. 2015. 60 f. TCC (Graduação) Curso de Ciências da Comunicação, Universidade de São Paulo, São Paulo, 2015. Disponível em: https://docplayer.com.br/14086124-Transliteracia-na-palma-da-mao-o-smartphone-naeducacao-do-seculo-xxi.html. Acesso em: 04 abr. 2020.

POZO, Juan Ignacio. Aprendizes e Mestres: a nova cultura da aprendizagem. Tradução Ernani Rosa. Porto Alegre: Artmed Editora. 2008. 
REINALDO, Francisco; MAGALHÃES, Demétrio R.; REIS, Luis P.; GAFFURI, Stefane; FREDDO, Ademir; HALLAL, Renato. Uso de smartphones na educação: Avaliação por grupos focais. CIAIQ2016, Porto, v. 1, 2016. Disponível em:

https://proceedings.ciaiq.org/index.php/ciaiq2016/article/view/668/657. Acesso em: 08 mai. 2020.

SANTOS, Ana Lúcia dos; ROCHA, Karla Marques da; LINCK, Jean Olivier. Tecnologias de informação e comunicação na educação. CIET: EnPED, [S.1.], maio 2018. Disponível em: https://cietenped.ufscar.br/submissao/index.php/2018/article/view/184. Acesso em: 04 de 04 mar. 2020.

SANTANA, José Ernandes Oliveira de. Matemática aplicada a Química. 2016. 96 f. Dissertação (Mestrado) - Curso de Acessar O Diretório" do Portal do Dgp, Universidade Federal do Ceará, Fortaleza, 2016. Disponível em:

http://www.repositorio.ufc.br/bitstream/riufc/22152/1/2016 dis \%20jeosantana.pdf. Acesso em: 05 mar. 2020.

SILVA, Heitor Felipe da; CARVALHO, Ana Beatriz Gomes. Ações educacionais em informática: Breve histórico da informatização da Educação Brasileira às ações em tecnologias educacionais na Rede de Escolas Municipais do Recife. Anais

Ctrl+E. Mamanguape: Ctrl+e 2017, p. 238 - 249, 2017. Disponível em: http://www.repositorio.ufc.br/bitstream/riufc/22152/1/2016_dis_\%20jeosantana.pdf. Aceso em: 08 mar. 2020.

SILVA, Patrycia Abadia da; LIMA, Cacilda Alves Miranda de; ALBUQUERQUE, Orlando; SILVA, Claúdio Pereira da. Principais aplicativos para smartphones no ensino de química. CIET:EnPED, [S.1.], maio, 2018. Disponível em:

https://cietenped.ufscar.br/submissao/index.php/2018/article/view/274. Acesso em: 12 dez. 2019.

SILVA, Patrícia Fernandes; SILVA, Thiago Pereira da; SILVA, Gilberlândio Nunes da. StudyLab: Construção e Avaliação de um aplicativo para auxiliar o Ensino de Química por professores da Educação Básica. Revista Tecnologias na Educação, [S.1.] v. 13, p. 1-12, 2015. Disponível em: http://tecedu.pro.br/wp-content/uploads/2015/12/Art25-vol13dez2015.pdf. Acesso em: 01 fev. 2020.

SOUZA NETO, Alaim; MENDES, Geovana Mendonça Lunardi. Os Usos das Tecnologias Digitais na Escola: Discussões em torno da fluência digital e segurança docente. Revista eCurriculum, São Paulo, v. 15, n. 2, p. 504-523, 2017. Disponível em:

https://www.redalyc.org/pdf/766/76651641012.pdf. Acesso em: 12 fev. 2020.

SOUZA, Rita de Cássia de. Uma análise construcionista social da liberdade na educação. Horizontes, Dourados, v. 38, n. 1, p. 020034, 2020. Disponível em: https://revistahorizontes.usf.edu.br/horizontes/article/view/760/449. Acesso em: 15 mai. 2020.

TORI, Romero. Educação sem distância: as tecnologias interativas na redução de distâncias em ensino e aprendizagem. $2^{\mathrm{a}}$ ed. São Paulo. Artesanato Educacional LTDA, 2017. 
TORI, Romero. Tecnologia e metodologia para uma educação sem distância. EmRedeRevista de Educação a Distância, Porto Alegre, v. 2, n. 2, p. 44-55, 2016. Disponível em: https://www.aunirede.org.br/revista/index.php/emrede/article/view/64. Acesso em: 14 mai. 2020.

VIEIRA, Hélida Vasques Peixoto; TAMIASSO-MARTINHON, Priscila; SIMÕES, André Luis; ROCHA, Angela Sanches; SOUSA, Célia. O Uso de Aplicativos de Celular como Ferramenta Pedagógica para o Ensino de Química. Revista Debates em Ensino de Química, Recife, v. 5, n. 1 ESP, p. 125-138, 2019. Disponível em:

http://www.ead.codai.ufrpe.br/index.php/REDEQUIM/article/view/2321. Acesso em: 15 de out. 2019.

ZIEDE, Mariangela Kraemer Lenz; SILVA, Ezequiel Theodoro da; PEGORARO, Ludimar; CANALLE, Edilson Marino; SILVA, Andreza de Oliveira Meireles da; CARVALHO, Aline Fernanda Wodonos de. Tecnologias digitais na Educação Básica: desafios e possiblidades.

RENOTE-Revista Novas Tecnologias na Educação, Porto Alegre, v. 14, n. 2, 2016.

Disponível em: https://www.seer.ufrgs.br/renote/article/view/70692/40129. Acesso em: 14 fev. 2020.

\section{NOTAS}

\section{AGRADECIMENTOS}

Ao PROFQUI/UFRPE, LEUTEQ, gestão da ECI Padre Manoel Otaviano e a C. M. R. Santos pela revisão textual.

\section{FINANCIAMENTO}

Financiado pelo(s) próprio(s) autor(es).

\section{CONTRIBUIÇÕES DE AUTORIA}

Resumo/Abstract/Resumen: Jocimario Alves Pereira e Bruno Silva Leite Introdução: Jocimario Alves Pereira e Bruno Silva Leite Referencial teórico: Jocimario Alves Pereira e Bruno Silva Leite Análise de dados: Jocimario Alves Pereira e Bruno Silva Leite Discussão dos resultados: Jocimario Alves Pereira e Bruno Silva Leite Conclusão e considerações finais: Jocimario Alves Pereira e Bruno Silva Leite Referências: Jocimario Alves Pereira e Bruno Silva Leite Revisão do manuscrito: Jocimario Alves Pereira e Bruno Silva Leite Aprovação da versão final publicada: Jocimario Alves Pereira e Bruno Silva Leite

\section{CONFLITOS DE INTERESSE}

Os autores declararam não haver nenhum conflito de interesse de ordem pessoal, comercial, acadêmico, político e financeiro referente a este manuscrito.

DISPONIBILIDADE DE DADOS DE PESQUISA

O conjunto de dados que dá suporte aos resultados da pesquisa foi publicado no próprio artigo.

\section{CONSENTIMENTO DE USO DE IMAGEM}

Não se aplica.

\section{COMO CITAR - ABNT}

PEREIRA, Jocimario Alves; LEITE, Bruno Silva. Percepções sobre o aplicativo FOQ1 Química por estudantes de uma escola pública. REAMEC - Rede Amazônica de Educação em Ciências e Matemática. Cuiabá, v. 9, n. 1, e21001, janeiro-abril, 2021. DOI: 10.26571/reamec.v9i1.11227. 


\section{COMO CITAR - APA}

Pereira, J. A., \& Leite, B. S. (2021). Percepções sobre o aplicativo FOQ1 Química por estudantes de uma escola pública. REAMEC - Rede Amazônica de Educação em Ciências e Matemática, 9 (1), e21001. DOI: 10.26571/reamec.v9i1.11227.

\section{LICENÇA DE USO}

Licenciado sob a Licença Creative Commons Attribution-NonCommercial 4.0 International (CC BY-NC 4.0). Esta licença permite compartilhar, copiar, redistibuir o manuscrito em qualquer meio ou formato. Além disso, permite adaptar, remixar, transformar e construir sobre o material, desde que seja atribuído o devido crédito de autoria e publicação inicial neste periódico.

\section{DIREITOS AUTORAIS}

Os direitos autorais são mantidos pelos autores, os quais concedem à Revista REAMEC - Rede Amazônica de Educação em Ciências e Matemática - os direitos exclusivos de primeira publicação. Os autores não serão remunerados pela publicação de trabalhos neste periódico. Os autores têm autorização para assumir contratos adicionais separadamente, para distribuição não exclusiva da versão do trabalho publicada neste periódico (ex.: publicar em repositório institucional, em site pessoal, publicar uma tradução, ou como capítulo de livro), com reconhecimento de autoria e publicação inicial neste periódico. Os editores da Revista têm o direito de proceder a ajustes textuais e de adequação às normas da publicação.

\section{PUBLISHER}

Universidade Federal de Mato Grosso. Programa de Pós-graduação em Educação em Ciências e Matemática (PPGECEM) da Rede Amazônica de Educação em Ciências e Matemática (REAMEC). Publicação no Portal de Periódicos UFMT. As ideias expressadas neste artigo são de responsabilidade de seus autores, não representando, necessariamente, a opinião dos editores ou da referida universidade.

\section{EDITOR}

Marcel Thiago Damasceno Ribeiro

\section{HISTÓRICO}

Submetido: 01 de outubro de 2020.

Aprovado: 28 de novembro de 2020

Publicado: 13 de janeiro de 2021. 